\title{
Presentation
}

\section{CENTENÁRIO DE CLARICE LISPECTOR}

Em 2020, comemoramos o centenário de Clarice Lispector. São exatos 100 anos da vida de uma escritora que, com sua mão tocada pelo fogo concebeu e produziu uma literatura inquietante, questionadora e fascinante. Clarice Lispector nunca foi tão atual! Considerando os dias difíceis que atravessamos, política e existencialmente falando, a obra de Clarice Lispector jorra como água viva sobre o angustiante e incerto ser e estar no mundo que nos impele a decisões urgentes, sem que, todavia, percamos de vista a reflexividade.

Esse número especial em comemoração aos 100 anos de Clarice Lispector faz com que nos voltemos, ainda mais, para a obra de uma escritora ímpar, que "não escrevia para agradar", que, antes, escrevia "como se fosse para salvar a vida de alguém", que "nasceu incumbida" e escrevia para se livrar ("eu escrevo e assim me livro de mim e posso então descansar"). Mas, se ao escrever ela se livrava, a escrita dela não livra o leitor. O leitor que lê o livro de Clarice Lispector se defronta com a espécie de livro de que fala Franz Kafka a Oskar Pollak, em correspondência de 1904: “Acho que só devemos ler a espécie de livros que nos ferem e trespassam. (...) nós precisamos de livros que nos afetam como um desastre, que nos magoam profundamente, como a morte de alguém que amávamos mais do que a nós mesmos, como ser banido para uma floresta longe de todos. Um livro tem que ser como um machado para quebrar o mar de gelo que há dentro de nós" (s/d, p. 9).

O encontro com a obra de Clarice é, assim, desastroso. Seremos, inevitavelmente afetados por esse choque, essa sacudidela, esse encontrão - no sentido literal do vocábulo.

No artigo que abre nosso número, intitulado "Commentaire Composé: leitura existencialista de um excerto da prosa de ficção de Clarice Lispector”, Hugo Lenes Menezes utiliza o método francês de análise para iluminar um fragmento de Perto do coração selvagem, primeiro romance de Clarice Lispector. Esse exercício interpretativo se concentra nas relações de afinidade entre Clarice e Sartre, tomando como ponto de parentesco a questão da liberdade nos autores em questão.

Em "Uma leitura de $A$ maşã no escuro, o livro de/sobre Martin", Guido Arosa e João Camillo Penna discutem a relação entre crime e linguagem. Os autores elaboram uma reflexão sobre o romance $A$ maçã no escuro, escrito ainda na década de 1950, um dos textos menos estudados de Clarice Lispector. Ao problematizar a relação entre crime e linguagem os 
críticos defendem que um dos modos de ler esse texto assim como outros textos curtos de Clarice é pelo viés do questionamento do próprio gênero e de seus limites.

No artigo "Por fora - viu no espelho - ela era uma coisa seca como um figo seco: beleza e identidade cambiante em um conto de Clarice Lispector", Juliana Gevarson e Helaine Ribeiro efetuam uma leitura do conto "A procura de uma dignidade". As críticas conseguem articular uma interpretação em que a questão da identidade se articula com a discussão da beleza, assim como também apontam como o texto clariceano efetua rechaço potente ao sistema patriarcal e a um modelo hegemônico de como ser mulher.

Outro artigo se volta para a discussão da linguagem, "A metamorfose de Clarice Lispector”. Ermelinda Maria Araújo Ferreira discute a questão da metalinguagem em Clarice, demonstrando a virada que ocorre em sua obra a partir da publicação de Laços de família. A interpretação se concentra, sobretudo, nos textos "A quinta história" e A paixão segundo G.H., demonstrando como a figura do inseto que aparece nos textos pode ser lido como um potencial que deflagra a reflexão sobre a metalinguagem, que está presente na Clarice cronista e na escritora de romances.

Em "Eu ou minha alma: escolhas subjetivas no universo ficcional de Clarice Lispector”, Gilson Antunes da Silva se vale do aporte teórico da psicanálise e da filosofia trágica de Nietzsche para percorrer alguns textos curtos e o romance $A$ paixão segundo G.H. evidenciando as tensões entre o universo apolíneo e as dimensões dionisíacas e afirmativas da escrita clariceana.

Em "O sistema da moda em Clarice Lispector", a partir de uma análise semiológica da obra de Clarice Lispector, sobretudo com base na teoria das máquinas desejantes de Deleuze e Félix Guattari, Olga Kempinska discute como se dá a configuração da moda nos textos não ficcionais de Clarice Lispector, mais especificamente nos textos de Correio feminino nos quais a escritora, conforme Kempinska, combina o tom poético do ensaio e do conto com o olhar crítico de caráter sociopsicológico.

"Perto do coração da Água viva", da autoria de Ayane Sobral e Lucia Castello Branco, parte do romance inaugural de Clarice Lispector, Perto do coração selvagem (1943), considera o feminino, numa perspectiva da Psicanálise, como um "mais além" do falo e do próprio masculino - como um "terceiro sexo", "feminino de ninguém" - o que para as autoras se evidencia sobretudo em Água viva (1973), livro no qual é possível a ex-sistência da Mulher como o substantivo feminino de ninguém.

Americo Saraiva em "Centro complexo e semovente: a linguagem e a vertigem Clarice Lispector" efetua uma leitura de Clarice Lispector, em especial do texto Água viva, 
demonstrando como a escritora brasileira foi uma artesã da deformação da linguagem. Ao defender uma leitura de Clarice como essa escritora da deformação, este trabalho contribui também para uma leitura que mostra como a escritora brasileira atacava as formações ideais, que obrigam certos modos de ser e estar no mundo e ao mesmo tempo rechaçam outras formas de existência menos dogmáticas.

No texto intitulado "O revés judaico nos contos de Rawet e Clarice", Thays Freitas de Almeida Pena e Stefania Rota Chiarelli, partindo da premissa de que há várias formas de ser judeu, reflete sobre as marcas da tradição judaica na trajetória dos escritores Samuel Rawet e Clarice Lispector, demonstrando o modo singular com que cada escritor experiencia o judaísmo e como este se dá a ver em suas respectivas obras.

Em “A narrativa de Clarice Lispector no coração selvagem do Brasil no século XX: alguns aspectos sociopolíticos, Francisco Carlos Carvalho da Silva e Geórgia Gardênia Brito Cavalcante Carvalho, elegendo na obra clariceana textos de gêneros diversos: crônicas, novela e contos, debruçam-se sobre aspectos sociopolíticos que permeiam a obra da escritora. Os autores defendem que, ao contrário do que apontou parte da crítica, o corpus analisado evidencia que Clarice Lispector produziu, sim, uma literatura engajada.

Ainda dentro de um enfoque sociopolítico, "Servidão e superação: um estudo acerca da presença da empregada doméstica na obra de Clarice Lispector" discute a presença da empregada doméstica na obra da escritora. Para Patrícia Ferreira Alexandre de Lima, a aparição frequente de empregadas domésticas na obra de Lispector se justifica pelo fato de que a maioria das personagens clariceanas é composta por mulheres, bem como pelo fato de o trabalho doméstico ser, quase sempre, realizado por pessoas do sexo feminino. A autora argumenta que Clarice dá a ver a seu leitor, a partir da criação de personagens mulheres que desempenham serviços domésticos, sua literatura comprometida com classes menos favorecidas, o que desconstrói a ideia de que ela não passava de uma escritora alienada, fechada em seu mundo particular.

O artigo "A potência do silêncio em Clarice Lispector", por sua vez, engendra um modo de ler Clarice por meio de uma temática consagrada em sua crítica, a saber, a discussão da linguagem e do silêncio em seus textos. Essa volta à temática do silêncio ocorre, contudo, por duas linhas de força diferentes, que Cristiane Côrtes defende ser a incapacidade da representação e a constatação da alteridade que aparece, sobretudo, no derradeiro livro de Clarice Lispector, $A$ hora da estrela.

Em “A hora da escrita: Clarice Lispector, linguagem e metaficção", Raimunda Maria Santos, Joelma de Araújo Silva Resende e Sebastião Alves Teixeira Lopes examinam o fazer 
literário de Clarice Lispector em $A$ hora da estrela (1977), último livro publicado pela escritora. Ressaltando a força estética da linguagem da escritora, os autores recorrem aos conceitos de (auto)ficção e metaficção para demonstrar como Lispector transforma a própria existência e labor em matéria literária.

O texto "A roda da escritura em $A$ bora da estrela, de Clarice Lispector: uma engrenagem complexa", à luz da teoria genética denominada roda da escritura, elaborada por Philippe Willemart (2009), versa sobre as quatro instâncias da roda da escritura: escritor, scriptor, narrador e autor, observando como cada uma delas aparece em $A$ hora da estrela. Para João Paulo Vicente Prilla, o fato de $A$ bora da estrela consistir em "uma história dentro da história" aponta para a complexidade e o dinamismo estabelecidos pelo movimento das instâncias escritor, scriptor, narrador e autor.

Em "A mercantilização da cultura na narração de Rodrigo S.M., em $A$ bora da estrela, de Clarice Lispector", Bárbara Del Rio Araújo analisa a relação entre a configuração narrativa de $A$ hora de estrela que, segundo ela, apresenta "novas tendências sobre o uso da linguagem", com o atuante paradigma da indústria cultural na composição estética e com a problemática da identidade nacional. A autora defende que as dificuldades colocadas pelo narrador interposto Rodrigo S.M. não somente "suscitam discussões para além da escrita de si e da alteridade", mas também desvelam 'o sentimento acabrunhador da posição em falso de tudo o que concerne à cultura brasileira'.

Alex Keine de Almeida Sebastião, em "O manuscrito de Um sopro de vida: imagens da letra", investiga a relação entre o manuscrito e o livro Um sopro de vida, publicado postumamente em 1978, com a colaboração de Olga Borelli. O autor, partindo de consulta ao acervo de Clarice Lispector, mantido pelo Instituto Moreira Salles (IMS), indaga a participação de Olga Borelli na elaboração de Um sopro de vida, questionando sobre a autoria do livro publicado. Sebastião esclarece ainda que, embora as questões relacionadas à criação sejam muito discutidas pela Crítica Genética, o propósito dele não é realizar uma edição crítica do livro em questão, mas tomar o manuscrito como uma obra de arte autônoma e que pode, inclusive, apontar para vários outros livros jamais publicados.

Por fim, em “Outro possível retrato: entrevista com Teresa Cristina Montero Ferreira, Biógrafa de Clarice Lispector", Sandro Adriano da Silva entrevista a autora da biografia intitulada Eu sou uma pergunta: uma biografia de Clarice Lispector, publicada em 1999, pela editora Rocco. O entrevistador apresenta diversas questões à biógrafa com o intuito de captar quem é Clarice Lispector. No entanto, embora, a biografia escrita por Teresa Montero tenha respondido muitas questões que perpassam a vida e a obra de Lispector, o próprio título - Eu 
sou uma pergunta - insinua, de antemão, que Clarice continua sendo para seus leitores um mistério, uma pergunta que evoca outras perguntas para, só assim, delinear outros possíveis retratos.

Os trabalhos aqui apresentados também são, todos eles e cada um a seu modo, tentativas de oferecer respostas, ainda que parciais, provisórias, para a grande pergunta que Clarice Lispector sustenta com sua obra.

Prof. Dr. Luiz Carlos Gonçalves Lopes (Cefet - MG)

Profa. Dra. Maria das Graças Fonseca Andrade (Uesb) 